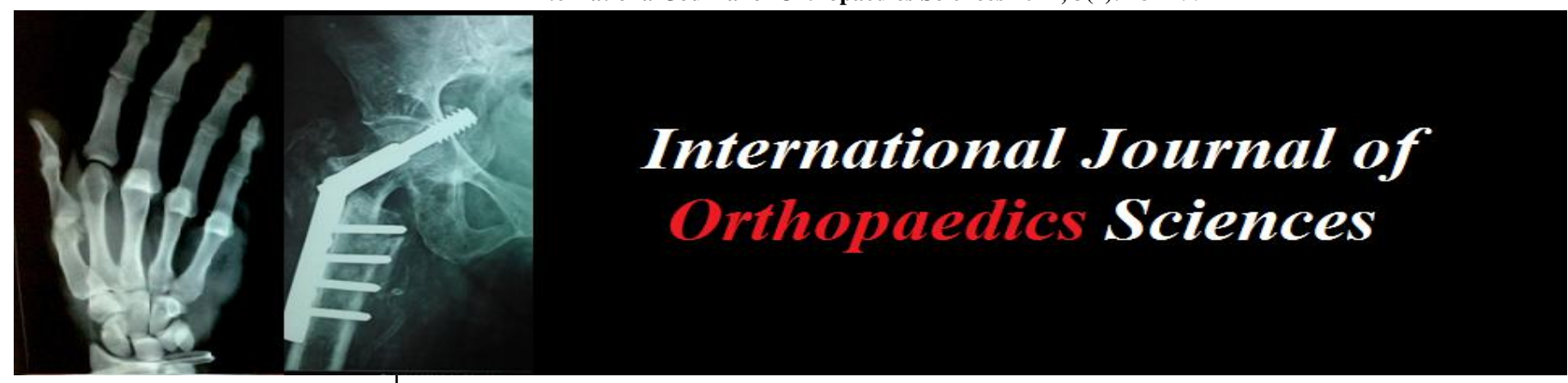

ISSN: $2395-1958$

IJOS 2017; 3(4): 787-799

(C) 2017 IJOS

www.orthopaper.com

Received: 20-08-2017

Accepted: 21-09-2017

Dr. Vishwanath C

Department of Orthopaedics, Adichunchangiri Institute of Medical Sciences, B G Nagar, Mandya, Karnataka, India

Dr. Sushanth B Mummigatti Orthopaedic Specialist, Aster CMI Hospital, Airport Road, Bengaluru, Karnataka, India

Correspondence

Dr. Vishwanath C

Department of Orthopaedics, Adichunchangiri Institute of Medical Sciences, B G Nagar, Mandya, Karnataka, India

\section{Surgical management of compound fracture tibia using an unreamed interlocking nail}

\author{
Dr. Vishwanath C and Dr. Sushanth B Mummigatti
}

DOI: https://doi.org/10.22271/ortho.2017.v3.i4k.110

\section{Abstract}

Background and Objectives: With increasing number of vehicles on the roads in India, complex trauma cases caused by traffic accidents have increased progressively. Fracture Tibia are among the commonest fractures sustained in road traffic accidents due to the subcutaneous nature of the tibia, they are frequently open and contaminated fractures. Due to the poor blood supply and poor soft tissue coverage these fractures are frequently complicated by delayed union, malunion, non-union and infection.

Controversy exists as to the optimal method of stabilization of compound fractures of Tibia. External Fixation devices had been quite popular in the management of these fractures, but lately unreamed intramedullary nail is being used as the initial management of these fractures as external fixation devices are associated with complications such as communition, displacement, soft tissue injury and pin tract infections moreover wound management and skin closing procedures are easier with Intramedullary nailing, Studies have shown that reaming disrupts the cortical blood flow to a greater extent than the Unreamed nails thereby increasing the susceptibility to infection. When comparing the Unreamed IM nail to the Reamed IM nail, the Unreamed nail with interlocking may provide the same stability as a closely fitting tubular nail but without the danger of jamming. Thus considering all these studies, the Unreamed IM Nail can be used for the management of Compound fractures of Tibia.

This study was conducted at the Department of Orthopaedics, Adichunchanagiri institute of medical sciences to evaluate the results of interlocking intramedullary nailing using an unreamed nail in the treatment of the compound fractures of tibia. It was done to compare the advantage of using an interlocking intramedullary nailing without reaming in the treatment of compound fractures of tibia with various studies in terms of time required for union, rate of malunion and malrotation, infection and range of motion of knee and ankle.

Materials and Methods: This study was performed on 50 compound fractures of tibia with an unreamed interlocking intramedullary nail at Adichunchanagiri Institute of Medical Sciences \& Research centre after attaining ethical clearance. All the cases selected were fresh fractures and mostly traumatic in nature. The procedure was done as early as possible and the secondary procedures of Dynamisation, skin grafting and musculocutaneous flap were done as and when needed.

The cases were followed up for an average period of 18 months with 4 visits ( 6 weeks, 3 months, 6 months and 12 months)

Results: Compound fractures of the tibia managed using an unreamed interlocking intra medullary nail gave good functional results and patient satisfaction. It involved minimal surgical trauma and less blood loss. It provides the advantage of early ambulation, lower rates of infection, non-union, mal union and delayed union compared to other treatment modalities. It allows early weight bearing and shorter hospital stay.

Interpretation and Conclusions: It was concluded that early interlocking intra medullary nailing using an unreamed nail with immediate soft tissue coverage resulted in good fracture union and low rates of complications compared to other modalities of treatment. It is cost effective with short hospital stay and facilitates earlier return to work. Over all morbidity is reduced and better patient satisfaction noted.

Keywords: Interlocking intramedullary nailing unreamed, non-union, dynamization

\section{Introduction}

"The primary objective in the management of an open fracture is union with prevention or eradication of wound sepsis"- Gustillo et al. As urbanization and industrialization are progressing with time, with rapid increase in traffic, incidence of high velocity trauma are also increasing ${ }^{[1]}$. Tibial diaphyseal fractures are the commonest long bone fractures encountered 
by most ortho paedic surgeon's. In an average population there are about 26 tibial diaphyseal fractures per 1 lakh population per year. Males are more commonly affected than females with male incidence being about 41 per 1 lakh per year, and female incidence about 12 per 1 lakh per year. There is a bimodal distribution of tibial fractures with a preponderance of young males ${ }^{[1]}$.

Because of its very location ie: two third of the tibial surface is subcutaneous throughout most of its length, compound fractures are more common in tibia than in any other major long bone ${ }^{[2]}$. Further more the blood supply of tibia is more precarious than other long bones due to inadequate muscle coverage ${ }^{[3]}$.

Tibial fractures may be associated with compartment syndrome, vascular or neural injury. The presence of hinge joints at the knee and the ankle, allows no adjustment for rotatory deformity after fracture ${ }^{[4]}$. Because of the high prevalence of complications associated with these fractures, management is quite difficult, and the optimum method of treatment still is a subject of controversy.

There are five principle causes of tibial diaphyseal fractures; direct blow, assaults, sports injuries, falls, motor vehicle accidents and gun shot injuries ${ }^{[1]}$. The important factors in prognosis are

1. amount of initial displacement

2. degree of communition

3. whether infection has developed and

4. severity of soft tissue injury excluding infection

5. duration of time lapsed for the initiation of treatment.

"Every fracture is an individual problem, and the decision to treat it conservatively or by internal fixation should be based on a realistic assessment of the advantages and the hazards of each method in the circumstances of that particular case. This calls for a high degree of clinical judgement which is harder to acquire or to impart than technical virtuosity in the operating theatre" [3]

Management of the fractured tibia requires the widest experience, greatest wisdom and the best of clinical judgement in order to choose the most appropriate treatment for a particular pattern of injury ${ }^{[4]}$.

Among the various modalities of treatment such as conservative gentle manipulation and use of short leg or long leg cast, open reduction and internal fixation with plates and screws, intra medullary fixation (including Ender pins, intramedullary nails, and interlocking intramedullary nails with reaming or without reaming), and external fixation techniques like ring fixator, surgeon should be capable of using all these techniques and must weigh advantages and disadvantages of each one and adapt the best possible treatment $^{[4]}$.

The best treatment should be determined by a thoughtful analysis of morphology of the fracture, the amount of energy imparted to the extremity, the mechanical characteristics of the bone, the age and general conditions of the patient and most importantly the status of the soft tissues (the skin, muscle, tendons, ligaments and associated neurologic and vascular structures of the leg) ${ }^{[1]}$.

Three goals must be met for the successful treatment of open fractures of tibia. The prevention of infection, the achievement of bony union, maintains limb length and the restoration of function and prevention of deformity ${ }^{[1]}$. These goals are interdependent and usually are achieved in the chronologic order given. For example failure to prevent infection promotes delayed union or non-union, chronic osteomyelitis and delays functional recovery of the limb. Immobilization in a plaster cast has been used most commonly in the past but it does not always maintain the length of the tibia and it leaves the wound relatively inaccessible and rehabilitation will also be difficult due to stiffness.

Open reduction and internal fixation with plates and screws has yielded high rates of infection. This method may be selected with more severe or local injuries, associated displaced intra articular fractures of knee and ankle ${ }^{[5]}$.

External fixation, considered the treatment of choice by many truamatologists, has the disadvantages of the bulky frames and frequent pin track infections, non-unions, and malunions. 6,9 , and are cumbersome to the patients ${ }^{[6]}$. The author in his text, closed treatment of common fractures said that he believed the eventual solution to the tibial fractures would be a nonreamed intramedullary nail ${ }^{[7]}$.

The intramedullary nailing locked or unlocked has become an attractive option since image intensifier has made closed intramedullary nailing possible. Nail is a load sharing device and is stiff to both axial and torsional forces. Closed nailing involves least disturbance of soft tissue, fracture hematoma and natural process of bone healing as compared to other forms of internal fixation ${ }^{[3]}$.

Intramedullary nails such as Lottes and Ender nails used without reaming have been employed successfully in the treatment of open tibial fractures and have been associated with low rates of post operative infection. They are however contraindicated for communited fractures as there tends to be shortening or displacement of such fractures around these small nails ${ }^{[6]}$. The locking of intramedullary nails to the major proximal and distal fragments decreases the prevalence of malunion of communited fractures. Until recently, however all interlocking intramedullary nailing involved reaming, which destroys the medullary blood supply ${ }^{[2]}$.

The rate of infection after treatment of open tibial fractures with intramedullary nailing with reaming has been relatively high because reaming avascularizes the bone which is already avascular because of stripping of periosteal and soft tissue causing most investigators to discourage the use of this technique for grade II and III open tibial fractures ${ }^{[1]}$.

This led us to design a trial, to study the results of closed interlocking intramedullary nailing using an unreamed nail in the treatment of compound fracture of the tibial shaft which preserve the endosteal blood supply and causes minimal damage to the periosteal blood supply which is already jeopardized.

\section{Aims and Objectives}

1. To study and evaluate the clinical outcome of compound fracture tibia with an unreamed intramedullary nail.

2. To evaluate the incidence of complications in these compound fractures as a result of unreamed intramedullary nailing.

3. To compare the efficacy of interlocking intramedullary nailing without reaming in treating compound fractures of tibia with other standard similar studies in terms of

- Time required for the union of fracture.

- Range of motion of ankle and knee joint.

- Rate of malunion and mal rotation

- Pain at the knee joint.

- Rate of infection.

- Failure of the implant.

- Soft tissue coverage 


\section{Surgical Anatomy}

The anatomy of the leg makes tibia susceptible to open fractures. The entire medial border is subcutaneous and is covered by skin and subcutaneous tissues. It also makes a tempting target for the enthusiastic surgeon, as the surgical approach to the tibia is simple ${ }^{[2]}$.

The anterior tibial border in the diaphyseal region of tibia is very dense and extends from tibial tuberosity proximally to just above the ankle joint distally. The subcutaneous prominence of tibia lends itself very readily to pin fixation due to lack of muscles, tendons traversing the anteromedial portion.

Muscles of leg: Tibia is surrounded by muscular envelop and is divided into four compartments by unyielding deep fascia of the leg.

\section{Anterior Compartment}

It contains the tibialis anterior, extensor digitorum longus, extensor hallucis longus and the peroneous tertius muscles. This anterior compartment also contains the anterior tibial artery and deep peroneal nerve. The tendons are close to the tibia and the fracture in this area may cause callus formation that comparatively restrict gliding of these tendons.

\section{Lateral Compartment}

Lateral compartment contains the muscles peroneous longus and peroneous brevis and they protect the fibular shaft except near the ankle.

\section{Posterior Compartment}

It is further divided into a superficial and a deep compartment. The muscles of this compartment are soleus, gastrocnemius, popliteus, tibialis posterior, flexor hallucis longus and flexor digitorum longus. The posterior tibial nerve, the posterior tibial artery and its large branch peroneal artery also run in the posterior compartment. Tibial fractures in the upper third are complicated by the compartment syndrome. This may occur more commonly in the anterolateral compartment and also the posterior compartment. The superficial posterior compartment contains the gastronemius, soleus muscle serving as a source for local muscle flaps, which helps in covering the soft tissue defects in the proximal and middle third of tibia. The posterior tibial artery is usually well protected. It is the major arterial supply after a severe open fracture and is a potential source for anastomosis with free flaps for soft tissue reconstruction of the leg.

\section{Interosseous Membrane}

This is a strong sheet of fibrous tissue, which closes the spaces between the tibia and fibula except at its upper end; where there is a small opening for the anterior tibial vessels.

\section{The Blood Supply}

The anterior and posterior tibial and peroneal arteries are the main blood vessels of the leg. The anterior tibial artery is one of the terminal branches of the popliteal artery and passes forward through the opening in the interosseous membrane to reach the anterior compartment, where it passes downwards on the interosseous membrane to terminate in the dorsalis pedis artery. The posterior tibial is the direct continuation of the popliteal artery. It passes downwards in the space between the deep flexor muscles and the calf muscle to terminate in the plantar arteries. The peroneal artery passes downward in close relation to the posterior surface of the tibia ${ }^{[1]}$.

Blood supply of the tibia as all other long bones is periosteal and endosteal. The periosteal blood supplies the outer third of the cortex, while the endosteal blood supplies the inner two third of the cortex. Periosteal blood supply comes from the surrounding musculature, while endosteal comes from the nutrient artery which is a branch of the posterior tibial artery at the soleal line. Usually the blood flow is centrifugal, however in case of a fracture when the endosteal blood supply is damaged, the flow is reversed and it changes from centrifugal to centripetal. When intramedullary nailing is done, the endosteal blood supply is interrupted. It is extremely important to preserve the soft tissue attachment. This is achieved by a closed intramedullary nailing ${ }^{[8]}$.

The nutrient artery divides into three ascending branches which supply the proximal two-third of the tibia, and gives a smaller descending branch which supplies the distal one-third of tibia. Hence, the proximal tibia has good endosteal blood supply, while the distal tibia has poor supply. The soft tissue attachments to the distal tibia are tendinous and are covered only by skin, making the periosteal blood supply scanty. This differential pattern of blood supply makes tibia susceptible to atrophic nonunion at the junction of the middle and distal third Unfortunately, majority of the open tibial fractures are at this junction ${ }^{[8]}$.
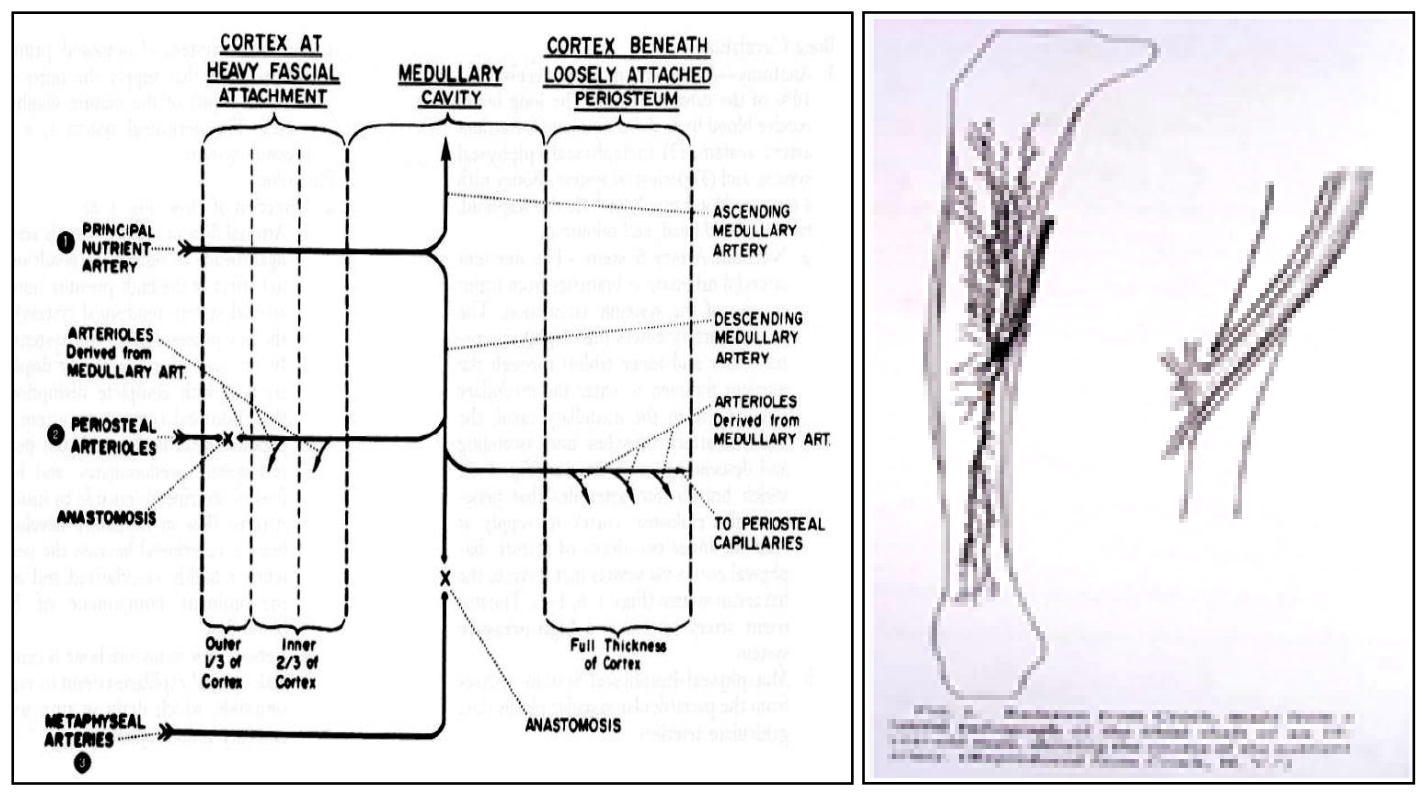

$789 \sim$ 


\section{Medullary Canal}

The medullary canal of the tibia is more in cross section than circular. Lack of curvature of the tibial medullary canal as against that of femur makes a longitudinal interference fit with an intramedullary nail very difficult.

\section{Role of Fibula}

When the fibula is intact the tibial fracture is stable. It maintains length in communited fractures and with bone loss, it acts as an internal splint ${ }^{[3]}$. But sometimes it also acts as a double -edged sword. For example, it prevents the union by preventing the collapse at the fracture site or in case of communited fractures, it can cause a varus angulation at the fracture site.

\section{Mechanism of Injury ${ }^{[2]}$}

For the tibial shaft fracture, a significant amount of energy must be applied in one of three modes.

a) Tensional injuries are more common with low energy trauma where the foot becomes fixed and the body rotates about this fixed point.

b) Three and four point bending forces produce short oblique transverse fractures. As the points of bending are spread further apart and as the amount of energy implied increases, communition increases and even segmental fractures develop.

c) Direct violence or high energy trauma as a result of motor vehicle and other road traffic accidents. Crushing injuries can be seen in RTA and industrial injuries where high concentration of energy is applied over a small area with resulting increased damage to bone and soft tissues.

The type of fibular fractures associated with that of tibia indicates the degree of soft tissue trauma involved. Severe communition of fibula with tibio-fibular diastasis indicates an unstable fracture with relative devascularisation of fracture fragments and attendant high rates of delayed, non or malunion.

\section{Design of Nonreamed Tibial Nails \\ 1) AO Unreamed Tibial Rod (UTN)}

The UTN is a solid nail made of cold worked implant steel /titanium alloy. Its surface has been roughened to enhance fatigue life. Its slightly flared proximal end has a diamond shaped cross section, where the anterior end is bevelled to prevent damage to the patellar ligament. The bend of the nail forms an angle of 9 degree, confirming to the anatomy of the tibia when correctly inserted. The proximal end has two medio-lateral locking holes; one round for static and one elongated for dynamic locking. Further, there are two holes for diagonal locking at $45 \mathrm{o}$ each to the frontal plane for additional anchoring of fractures in the proximal diaphysis. The round holes are $4 \mathrm{~mm}$ in diameter. Locking of the nails provides axial and rotational stability. The threaded cannulation of the proximal end accepts a sealing screw, which can be inserted after locking, and left in place to prevent in growth of soft tissue. The distal two thirds are straight; with a cross section corresponding to a triangle with a semicircular posterior base line. The posterior tapered tip of the distal end guides the nail along the posterior wall during insertion, reducing the risk of penetration of the cortex.

The distal end has two medio-lateral locking holes, and one between them in an A-P direction. At present the UTN is available in $8 \mathrm{~mm}$ and $9 \mathrm{~mm}$ diameters in stainless steel. Titanium alloy (TAN) nails are available in $8 \mathrm{~mm}, 9 \mathrm{~mm}$ diameter nails in blue colour and $10 \mathrm{~mm}$ diameter nails in green colour.

\begin{tabular}{|l|l|l|l|l|l|}
\hline & \multicolumn{2}{|c|}{ Stainless steel } & \multicolumn{3}{c|}{ Titanium alloy (TAN) } \\
\hline Nails & $8.0 \mathrm{~mm}$ dia & $9.0 \mathrm{~mm}$ dia & $\begin{array}{l}8.0 \mathrm{~mm} \text { dia } \\
\text { (blue) }\end{array}$ & $\begin{array}{l}9.0 \mathrm{~mm} \text { dia } \\
\text { (blue) }\end{array}$ & $10 \mathrm{~mm}$ (green) \\
\hline Locking & $3.9 \mathrm{~mm}$ dia & $3.9 \mathrm{~mm}$ dia & $3.9 \mathrm{~mm}$ dia & $3.9 \mathrm{~mm}$ dia & $4.9 \mathrm{~mm} \mathrm{dia}$ \\
bolts & & & (blue) & (blue) & (green) \\
\hline Drill bits & $3.2 \mathrm{~mm}$ dia & $3.2 \mathrm{~mm}$ dia & $3.2 \mathrm{~mm}$ dia & $3.2 \mathrm{~mm}$ dia & $4.0 \mathrm{~mm}$ dia \\
\hline
\end{tabular}

\section{2) AO Tubular Nail}

It is interlocking nail which is hollow and tubular. It is circular in cross section and flares at the top. It has positioning slots to lock the jig and has anterior flattened lip to decrease anterior knee discomfort. Its $2 \mathrm{~mm}$ wall thickness gives the nail a certain flexibility or bending and torsion necessary for fracture healing. The nail's conical proximal end has threads on the inner sides for the attachment of jig and extractor. Positioning grooves, precisely align the jig. The observation of stress distribution during insertion has resisted the curvature of 110 at the junction of the proximal third and he distal two third of the nail. The nail has two proximal holes for locking in medio-lateral direction and two distal holes in the antero-posterior direction. The hole diameter is $5 \mathrm{~mm}$ for 9 and $10 \mathrm{~mm}$ tibial nails and $4 \mathrm{~mm}$ for $8 \mathrm{~mm}$ nails. The nails available lengths is from $240 \mathrm{~mm}$ to $420 \mathrm{~mm}$ in $10 \mathrm{~mm}$ increments.

The locking bolts are self tapping

For $8 \mathrm{~mm}$ tibial nails $3.9 \mathrm{~mm}$ diameter locking bolts are used For $9,10,11 \mathrm{~mm}$ tibial nails $4.9 \mathrm{~mm}$ diameter locking bolts are used

\section{AO Interlocking Nail}

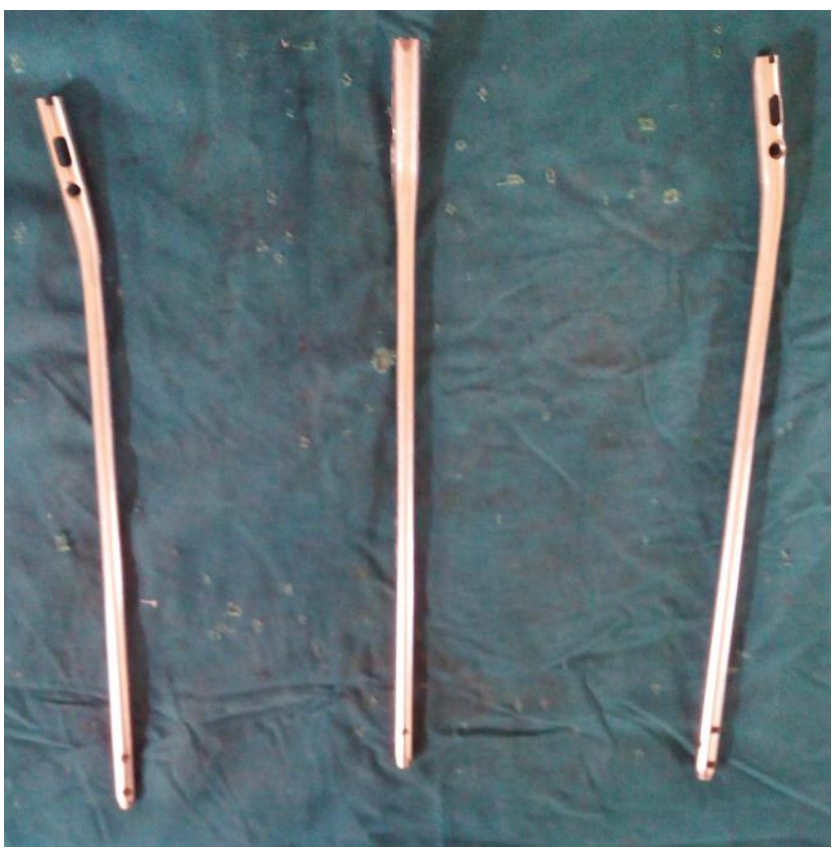

\section{3) Gross and Kempf small diameter nails}

They have the same clover leaf cross section and wall diameter as the standard nail, but without the partial posterior slot. They are available in diameter of 9 and $10 \mathrm{~mm}$ for tibia. all the nails are flared proximally to provide extra strength for insertion. There are two proximal locking holes for $4.5 \mathrm{~mm}$ shaft screws. The most proximal hole is directed antero- 
posteriorly, all the other holes are aligned in the coronal plane.

\section{4) Russel-taylor delta tibial nail}

It is a close sectioned stainless steel nail available in shaft diameters of 8,9 , and $10 \mathrm{~mm}$. The nail has a 150 anterior bend $45 \mathrm{~mm}$ from the top to allow the nail to enter the proximal portion the tibia. It has a $3 \mathrm{o}$ anterior bend in the distal $64 \mathrm{~mm}$ of the nail, which serves as ramp during insertion to reduce chances of posterior cortical communition. The proximal end of the nail is tapered to $12 \mathrm{~mm}$ to give extra strength for nail insertion. There are 4 locking holes; all in the coronal plane. $4.5 \mathrm{~mm}$ screws are used.

\section{Methods of Treatment}

In the past 25 years, a compound fracture of tibia \& fibula has been the most challenging problems of all long bone injuries. Due to progress in the management of this injury, we can now save limbs that would have been amputated 20 years ago.

In dealing with compound tibia fractures, these are the essential steps to be taken

1. Treat the open tibia fracture as an emergency. a delay of over 8 hours can allow a contaminated fracture to become infected.

2. Start intravenous antibiotic treatment before debridement and irrigation. Given cephazolin for type I fractures. Cephazolin and an aminoglycoside for type II and type III fractures. For injuries and or any type of soil contamination, add 10 million units of pencillin. If the patient is allergic to pencillin and cephalosporin, prescribe clindamycin or vancomycin.

3. Perform adequate debridement and irrigation by high volume low pressure. The goal is to convert a contaminated wound to a relatively clean wound. Repeat debridement in 48 to 72 hours is a must in type III open fractures.

4. Stabilize the fracture.

5. Reconstruct the soft tissue in 3 to 5 days. Early soft tissue reconstruction is the key to preventing wound sepsis. If the wound is left open for several days, hospital bacterial flora colonizes the wound and brings about deep sepsis.

6. Delay bone grafting until complete wound healing (4 to 6 weeks) is ensured. For type III open fractures, use autogenous bone graft. For type I and II fractures with fracture communition, autogenous bone grafting can be done at wound closure,

7. Begin early rehabilitation.

8. Recognize and effectively treat complications, e.g., compartmental syndrome, wound sepsis, and gas gangrene.

Every fracture of the tibial shaft must be assessed individually, and it can be dangerous to establish fixed routines of treatment.

1. Closed reduction and plaster immobilizations:

2. Pins and plaster:

3. Trans fixation by screws:

4. Fixation by plate and screws:

5. External skeletal fixation

6. Intramedullary Nailing

\section{Materials and Methods}

The present study was undertaken at the department of Orthopedics, Adichunchangiri Institute of Medical Sciences, B G Nagara, Mandya district after obtaining ethical clearance.
This study involved both male and female patients with compound fractures of tibia, who presented to Adichunchanagiri institute of medical sciences \& Research centre. 50 patients who had compound fractures of tibial shaft were treated with wound debridement and interlocking intramedullary nailing without reaming during the period from June 2013 to September 2016. Most of the patients were brought to the casualty. Remaining cases were admitted through the outpatient department. The Criteria for selection of the cases:

\section{Inclusion Criteria}

1. The patient with injuries associated with compound fracture of tibia up to compound GrIIIb

2. Age limit: 20 years to 70 years

3. Both males and females

\section{Exclusion Criteria}

1. Patients with pathological fractures

2. Patients with fractures lying proximal to tibial tuberosity

3. Patients with fractures within $5 \mathrm{~cm}$ of the distal articular surface of tibia

4. Patients with intraarticular extension of fractures

5. Patients with fracture tibia with significant bone loss

Fifty patients with compound tibia fracture were available for evaluation. The duration of follow-up ranged 18 months with 4 visits. There were 33 men and 17 women, ranging in age from 20 to 70 years old.27 right and 23 left tibia were fractured Most of the fractures were caused by high -velocity trauma.26 of the fractures were caused by motor cycle accidents, 17 by motor vehicle accidents, 07 pedestrian accidents.

The injuries were classified according to the system of Gustilo et al, 31 wounds were type II, 12 were type IIIA, and 07 were type IIIB. Location of the fracture, the tibia was divided into 5 zones of equal length; proximal third 03 fractures, 08 fractures were in proximal middle third, 19 fractures were in middle third, 13 fractures were in middle distal third, 07 fractures were in distal third. The predominant tibial fracture patterns were transverse in 11, oblique in 19 , and spiral in 07, and communited in 13 fractures.

On admission general condition of the patient was assessed with regards to hypovolemia, associated orthopedic or other systemic injuries and resuscitative measures were taken accordingly. All patients received analgesics in the form I.M injections, tetglob 500 I.U intramuscularly and antibiotics I.V. A thorough clinical examination was performed including detailed history relating to age, sex, occupation, mode of injury, past and associated medical illness. Patients were taken to the operating room for emergency irrigation and debridement of the open fracture. Swabs were taken from the wound and were sent for culture and sensitivity, thorough saline wash was given to the wound and all the foreign bodies over the wound were washed out. A severity of the open fractures determined the subsequent wound care and antibiotic treatment. Wounds were examined and primary closure was done for the wounds presenting within 6 hours of trauma and were found to be clean. A sterile dressing was given for wounds and limb was immobilized in the form of above knee plaster of Paris slab. Limb elevation over a pillow was given for all the patients. Routine investigations were done for all the patients. All patients were evaluated clinically and radiographically to assess for any other injuries. Radiographs were taken in two planes, A-P and Lateral views. 
I.V antibiotics, cephalosporins and aminoglycosides were started for all the patients, patients were operated as early as possible, once the general condition of the patients was stable and fit for surgery. Preoperatively the length of the nail was calculated clinically by assessing the measurement from the highest point of tibial tuberosity to highest point of medial malleous (TMD) and medullary canal was measured at the isthmus from the radiographs.

\section{Preoperative Preparation of the Patients}

- Patients were kept NPO for 8 to 10 hours before surgery

- Adequate amount of compatible blood if needed was arranged.

- Preparation of whole extremity /private parts and back was done.

- Written informed consent was taken

- Soap water enema H.S

- Anxiolytics H.S

- I.V antibiotics 30 minutes before the procedure.

- Shifting the patient 30 minutes before the surgery to operation theatre.

\section{Surgical Technique}

Patients were operated under spinal /general anesthesia. Patient is placed in Supine position over a C-Arm compatible operating table. The injured leg is positioned freely, with knee flexed 90o over the edge of operating table to relax the gastro soleus muscle and allow traction by gravity. The uninjured leg is placed in abduction, flexion and external rotation to ensure free movements of the image intensifier from A.P to lateral plane. The table is adjusted to comfortable operating height. The affected limb is thoroughly scrubbed from mid-thigh to foot with betadine scrub solution. Then limb is painted with betadine solution from mid thigh to foot. Rest of the body and other limb is properly draped with sterile drapes. Sterile glove are applied to the foot and steri-drape over the leg from knee joint to ankle.

\section{Determination of Nail Length}

Hold the radiographic ruler parallel to the tibial shaft in such a way that the proximal end comes to lie at the level of the insertion point. Mark the skin at the appropriate point. Position the image intensifier over the distal tibia. Align the measuring ruler at the skin marking with correct reduction, we can now read off the required nail length on the image intensifier picture at the level of former epiphyseal cartilage.

\section{Determination of Nail Diameter}

The marking on the radiographic ruler may be used to determine the diameter of the medullary canal. Position the square marking over the isthmus. If the transition to the cortex is still visible both to the left and right of the markings, the corresponding nail may be used.

Make a vertical patellar tendon splitting incision over skin extending from centre of the inferior pole of patella to the tibial tuberosity about $5 \mathrm{~cm}$ long. Split the patellar tendon vertically in its middle and retract it to reach the proximal part of tibial tuberosity. Next step is to determine the point of insertion, essential for the success of the procedure is the correct choice of the insertion point. As a general rule, the insertion point should be slightly distal to the tibial plateau, slightly medial and exactly in line with the medullary canal. If the insertion point is too distal, there is a danger of fracturing the distal cortex of the main proximal fragment, particularly in the case of rather proximal fractures.

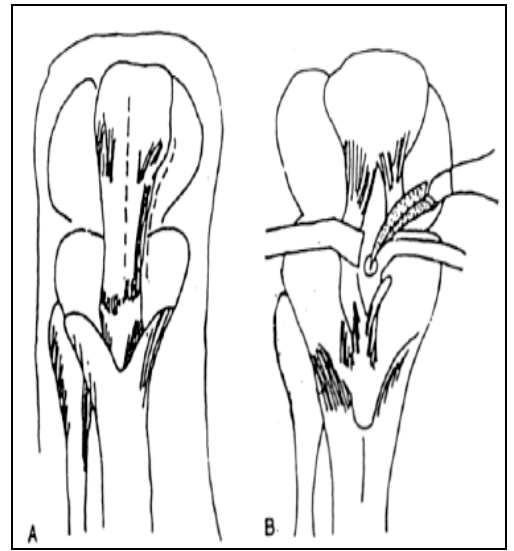

Insertion of IM nail through mladpatellar approach. It can also be approached medial to the patella tendon retracting the patellar tendon laterally

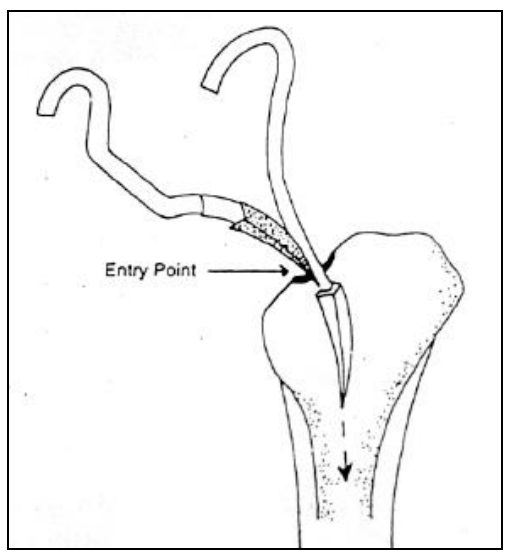

Paint of entry $1 \mathrm{~cm}$ above the tibial tubercle and perforating awl is allned with the medullary canal of tibio avolding the perforation of the posterior cortex

On the other hand, insertion too far proximally bears the risk of opening the knee joint, patella comes in the way of Jig or removal of nail may be difficult. After selecting the point of insertion, a curved bone awl is used to breach the proximal tibial cortex in a curved manner, so that from perpendicular position its handle comes to be parallel to the shaft. In the metaphyseal cancellous bone create an entry portal, making sure it is in line with the centre of medullary canal.

Point of entry is widened with a proximal reamer. After widening the medullary canal through the proximal $1 / 3^{\text {rd }}$ a guide wire of $3 \mathrm{~mm}$ diameter $\mathrm{x} 950 \mathrm{~mm}$ length is passed into the medullary canal of the proximal fragment and then reduce the fracture fragments under image intensifier by maintaining longitudinal traction in the line of tibia.

After reduction is achieved, the tip of guide wire is adjusted to pass into the distal fragment up to $0.5-1 \mathrm{~cm}$ above the ankle joint under image intensifier, confirm its containment within the tibia by anteroposterior and lateral views. Next step is to pass an assembled nail into the medullary canal over the guide wire.

\section{Procedure for AO solid UTN}

Insert the connecting screw through the insertion handle and coupling block. Ensure that the notches of the insertion handle fit into the grooves of the coupling block. The coupling blocks ensure a torque -resistant connection between insertion handle and nail. The insertion handle guides the nail and controls rotation during insertion. Apply the insertion handle to the medial side of the tibia for insertion and proximal locking. Tighten the whole assembly with 
combination wrench. Check that the assembly is firmly screwed together. Over tightening was not done.

Screw the inserter /extractor onto the proximal end of the connecting screw. Now introduce the unreamed tibial nail (UTN) as far as possible manually into the medullary canal with the help of the mounted insertion instruments. Use the image intensifier to check passing of the fracture line. Insertion can be aided by gentle blows with the slotted hammer. Insert the nail until it is slightly counter sunk in the bone. Confirm the placement of nail in-situ under image intensifier in both AP and lateral planes. Routinely we prefer distal locking be carried out first followed by proximal locking. If any fracture gap is present, we use the rebound technique to prevent diastasis.

The insertion Jig is used to locate the proximal locking bolts. The Jig of the insertion instrument is in the medial position. The skin is incised. Insert the trocar into the protection sleeve and push it down onto the surface of the tibia through the corresponding hole in the insertion handle. Remove the trocar and insert the drill sleeve. To prevent the drill bit from sliding off the tibial surface, ensure that the drill guide is sitting firmly on the bone and is not deflected by skin or soft tissue.

Drill through both cortices using the drill bit. We used the hand drill. Determine the required length of the locking blot by reading it directly off the calibrated drill bit by measuring with the depth gauge. When using the depth gauge, we added $2 \mathrm{~mm}$ to the measurement found so that the bolt can find purchase in the opposite cortex.

Insert the locking bolt with the hexagonal screw driver. Insert the second locking bolt in the same way. After screwing the insertion handle off the AO UTN, insert the sealing screw into the proximal end. This prevents in growth of tissue and thus facilitates later implant removal.

The AO UTN can be locked through one of the diagonal holes when the fracture is in the proximal diaphysis with attachment of the $45^{\circ}$ insertion handle. Incised wound is washed with betadine and normal saline. Patellar tendon is sutured with delayed absorbable sutures and skin is sutured.

Next step is distal locking. Several distal locking options are available to the surgeon in solid AO UTN. Using a free hand technique with an image intensifier provides a convenient method for targeting the distal locking holes.

The leg is extended over the table from its flexed position. The AO UTN has three distal locking holes, two medial lateral planes and one A-P plane. In Indian nail two distal locking holes are present, both are in A-P plane. The image intensifier is placed in the A-P position with the beam exactly at anterior aspect of the tibia with foot held in neutral position. Adjust the image intensifier until the most distal hole is clearly visible and appears completely round. Place the scalpel on the skin with the top of the blade over the centre of the hole to determine the stab incision point. Make a stab incision in addition, it also ensures that the surgeons hand remain outside the central radiation field of the image intensifier. Place the tip of the $2.5 \mathrm{~mm} \mathrm{~K}$ wire centered in the locking hole image

Adjust it until a $\mathrm{K}$ wire is in line with the X-ray beam and appears as radio-opaque solid circle in the center of the outer ring. Hit the $\mathrm{K}$ wire in to the bone. The DCP drill sleeve passed over the $\mathrm{K}$ wire. Hold sleeve firmly over the bone. The $\mathrm{K}$ wire removed and hole drilled through the both cortices with drill bit. Measure the hole with the depth gauge for locking bolts. Add $2 \mathrm{~mm}$ to this reading to ensure that the locking bolt will engage the far cortex. Insert the locking bolt and tighten with the hexagonal screw driver. Position of the screw is again confirmed under image intensifier. The entire leg and the fracture site visualized finally in both views for proper placement of nail. Incised wound is washed with betadine and saline, skin is sutured, sterile dressings were applied over the wound, Compression bandage given, tourniquet is, Capillary filling and peripheral arterial pulsations checked.

\section{Postoperative Care \\ Immediate}

- NPO 4-6 hours postoperatively.

- I.V fluids /blood transfusions

- I.V antibiotics and I.M analgesics

- Limb elevation over pillows

- Watch for active bleeding

- Active toe movements

- TPR/BP chart hourly

- Input /output chart

- Check X-ray of the operated tibia full length including knee and ankle joints in both A-P and lateral views.

Postoperatively elastocrepe bandage applied and limb elevation done over pillows, I.V antibiotics given for 7 days post-operatively, Culture from the wound if necessary sent, Switch over to oral antibiotics done on the 7 th postoperative day. Active knee, ankle and toe mobilization started after the effect of anesthesia wears off. Patient was allowed non weight bearing crutch walking on the immediate postoperative day. Skin sutures, were removed on 10th postoperative day. Depending upon the culture report and wound condition antibiotics are stopped or continued. Partial weight bearing crutch walking or with walker commenced after 10 days, depending upon the type of fracture and rigidity of fixation. Further follow up is done at 6 weekly intervals and each patient was individually assessed clinically and radiographically according to the proforma.

\section{AO Solid UTN Interlocking Instruments}

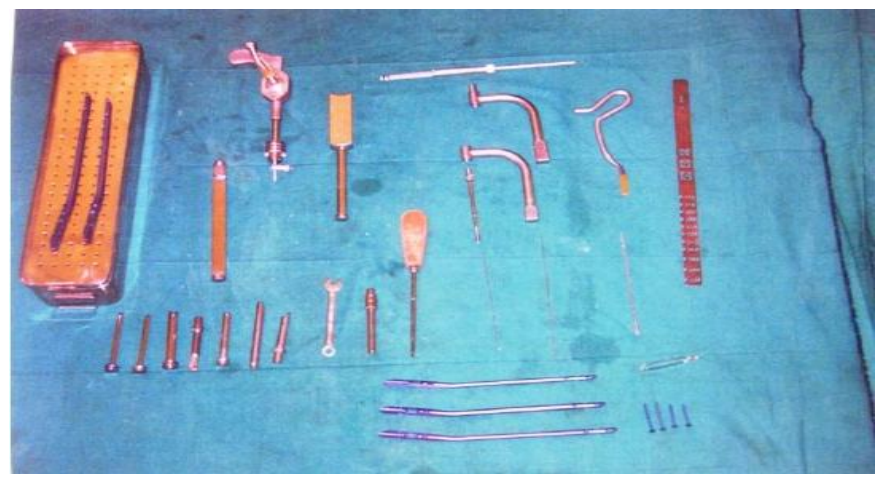

AO Nail Tubular Interlocking Instruments

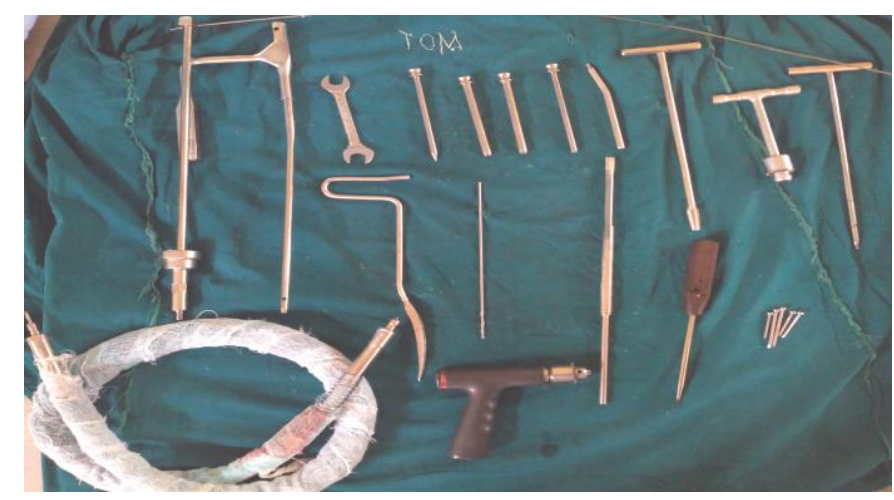


Photos of Operative Procedure

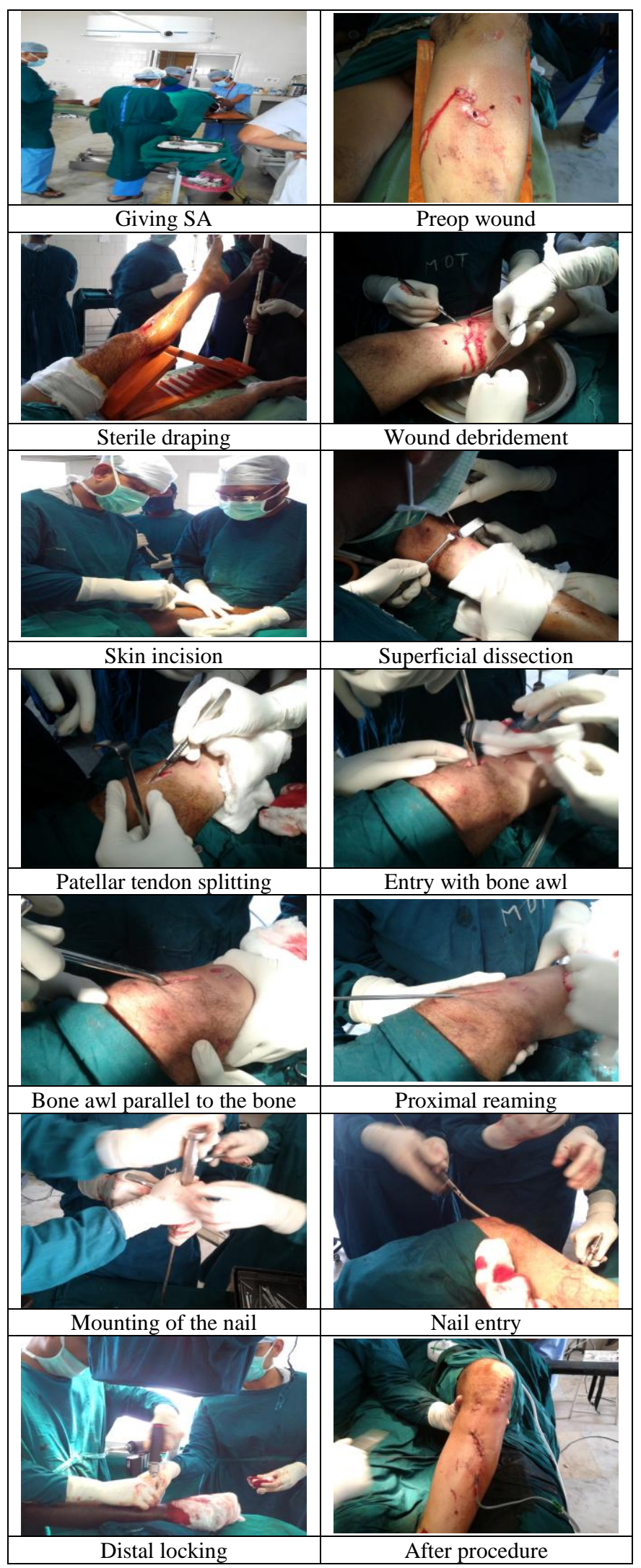

\section{Results}

The present study includes 50 compound fractures of the tibia surgically treated with closed interlocking intramedullary nailing without reaming from September 2013 to September 2016 at the department of orthopaedics at Adichunchanagiri institute of medical sciences, B G Nagara, Mandya district. The patients have been followed up for at least 18 months with 4 visits (6weeks, 3 months, 6 months and 12 months).
All these patients were available for follow up.

Table 1: Age distribution of patients studied

\begin{tabular}{|c|c|c|}
\hline Age in years & No. of patients & \% \\
\hline $20-30$ & 15 & 30 \\
\hline $31-40$ & 09 & 18 \\
\hline $41-50$ & 14 & 28 \\
\hline $51-60$ & 08 & 16 \\
\hline $61-70$ & 04 & 08 \\
\hline Total & 50 & 100 \\
\hline
\end{tabular}

Table 2: Gender distribution of patients studied

\begin{tabular}{|c|c|c|}
\hline Gender & No. of patients & \% \\
\hline Female & 17 & 34 \\
\hline Male & 33 & 66 \\
\hline
\end{tabular}

Table 3: Mode of injury

\begin{tabular}{|c|c|c|}
\hline Mode of injury & No. of patients & \% \\
\hline motor cycle accident & 26 & 52 \\
\hline motor vehicle accident & 17 & 34 \\
\hline pedestrian accident & 07 & 14 \\
\hline
\end{tabular}

Table 4: Side involved

\begin{tabular}{|c|c|c|}
\hline Side & No. of patients & \% \\
\hline Left & 23 & 46 \\
\hline Right & 27 & 54 \\
\hline Total & 50 & 100 \\
\hline
\end{tabular}

Table 5: Gustilo Type

\begin{tabular}{|c|c|c|}
\hline Gustilo Type & No. of patients & \% \\
\hline II & 31 & 62 \\
\hline IIIA & 12 & 24 \\
\hline IIIB & 07 & 14 \\
\hline Total & 50 & 100 \\
\hline
\end{tabular}

Table 6: Level Fracture

\begin{tabular}{|c|c|c|}
\hline Level Fracture & No. of patients & \% \\
\hline Proximal & 03 & 06 \\
\hline Proximal/Middle & 08 & 16 \\
\hline Middle & 19 & 38 \\
\hline Middle/Distal & 13 & 28 \\
\hline Distal & 07 & 14 \\
\hline Total & 50 & 100 \\
\hline
\end{tabular}

Table 7: Fracture pattern

\begin{tabular}{|c|c|c|}
\hline Fracture pattern & No. of patients & \% \\
\hline Communited & 13 & 26 \\
\hline Oblique & 19 & 38 \\
\hline Spiral & 07 & 14 \\
\hline Transverse & 11 & 22 \\
\hline Total & 50 & 100 \\
\hline
\end{tabular}

Table 8: Duration b/w Trauma \& Operation

\begin{tabular}{|c|c|c|}
\hline Duration b/w Trauma \& Operation & No. of patients & \% \\
\hline Less than 6 hours & 17 & 34 \\
\hline 6-24 hours & 25 & 50 \\
\hline$>$ 24 hours & 08 & 16 \\
\hline Total & 50 & 100 \\
\hline
\end{tabular}

Table 9: PWB

\begin{tabular}{|c|c|c|}
\hline PWB & No. of patients & \% \\
\hline Within 2 weeks & 19 & 38 \\
\hline 2-4 weeks & 28 & 56 \\
\hline More than 4 weeks & 03 & 06 \\
\hline Total & 50 & 100 \\
\hline
\end{tabular}


Table 10: FWB

\begin{tabular}{|c|c|c|}
\hline FWB & No. of patients & $\%$ \\
\hline Less than 8 weeks & 14 & 28 \\
\hline 8-16 weeks & 23 & 46 \\
\hline 16-24 weeks & 11 & 22 \\
\hline >24 weeks & 04 & 08 \\
\hline
\end{tabular}

Table 11: Secondary procedure

\begin{tabular}{|c|c|c|}
\hline Secondary procedure & No. of patients $(\mathbf{n = 2 0})$ & \% \\
\hline No & 21 & 42 \\
\hline Yes & 29 & 58 \\
\hline DYN & 14 & 28 \\
\hline SSG & 11 & 22 \\
\hline Soleus Flap & 04 & 08 \\
\hline
\end{tabular}

Table 12a: Union categories

\begin{tabular}{|c|c|c|}
\hline Union & No. of patients & \% \\
\hline Less than 4 months & 15 & 30 \\
\hline $4-8$ months & 21 & 42 \\
\hline $8-12$ months & 11 & 22 \\
\hline Non-union & 03 & 06 \\
\hline Total & 50 & 100 \\
\hline
\end{tabular}

Table 12b: Union Categories

\begin{tabular}{|c|c|}
\hline Type of union & No. Of patients \\
\hline Normal & 41 \\
\hline Delayed & 06 \\
\hline Non union & 03 \\
\hline
\end{tabular}

Table 13: Knee

\begin{tabular}{|c|c|c|}
\hline Knee & No. of patients $(\mathbf{n = 2 0})$ & \% \\
\hline Normal & 33 & 66 \\
\hline Abnormal & 17 & 34 \\
\hline$<75 \%$ & 11 & 22 \\
\hline$>80 \%$ & 4 & 08 \\
\hline$<80 \%$ & 2 & 04 \\
\hline
\end{tabular}

Table 14: Complications

\begin{tabular}{|c|c|c|}
\hline Complications & No. of patients & \% \\
\hline Infection & 13 & 26 \\
\hline Deep & 04 & 04 \\
\hline Superficial & 09 & 18 \\
\hline Knee pain & 06 & 12 \\
\hline Malunion & 05 & 10 \\
\hline Nonunion & 03 & 06 \\
\hline
\end{tabular}

Functional Results

Detailed analysis of function of the patient was done on the basis of following criteria by Johner and Wruh

Johner and Wruh's criteria for evaluation of final results

\begin{tabular}{|c|c|c|c|c|c|}
\hline S. No & Criteria & Excellent (left=right) & Good & Fair & Poor \\
\hline 1 & Non-union, osteitis, amputations & None & None & None & Yes \\
\hline 2 & Neurovascular disturbances & None & Minimal & Moderate & Severe \\
\hline \multirow[t]{4}{*}{3} & Deformity & & & & \\
\hline & Varus / Valgus & None & $2^{0}-5^{0}$ & $6^{0}-10^{0}$ & $>10^{0}$ \\
\hline & Anteroversion / Recurvation & $0^{0}-5^{0}$ & $6^{0}-10^{0}$ & $11^{0}-20^{0}$ & $>20^{0}$ \\
\hline & Rotation & $0^{0}-5^{0}$ & $6^{0}-10^{0}$ & $11^{0}-20^{0}$ & $>20^{0}$ \\
\hline 4 & Shortening & $0-5 \mathrm{~mm}$ & $6-10 \mathrm{~mm}$ & $11-20 \mathrm{~mm}$ & $>20$ \\
\hline \multirow[t]{4}{*}{5} & Mobility & & & & \\
\hline & Knee & Normal & $>80 \%$ & $>75 \%$ & $<75 \%$ \\
\hline & Ankle & Normal & $>75 \%$ & $>50 \%$ & $<50 \%$ \\
\hline & Subtalar & $>75 \%$ & $>50 \%$ & $>50 \%$ & - \\
\hline 6 & Pain & None & Occasional & Moderate & Severe \\
\hline 7 & Gait & Normal & Normal & Insignificant Limp & Significant limp \\
\hline 8 & Strenuous activity & Possible & Limited & Severely limited & Impossible \\
\hline 9 & Radiological union & Consolidated & Consolidated & Union & Not consolidated \\
\hline
\end{tabular}

The end results of all 50 cases are summarized here. All the cases had a follow up Of 18 months with 4 visits (6wks, 3months, 6months, 12 months)

Table 15: Results

\begin{tabular}{|c|c|c|}
\hline Results & No. of patients & \% \\
\hline Excellent & 31 & 62 \\
\hline Good & 10 & 20 \\
\hline Fair & 06 & 12 \\
\hline Poor & 03 & 06 \\
\hline Total & 50 & 100 \\
\hline
\end{tabular}


Case Series -01
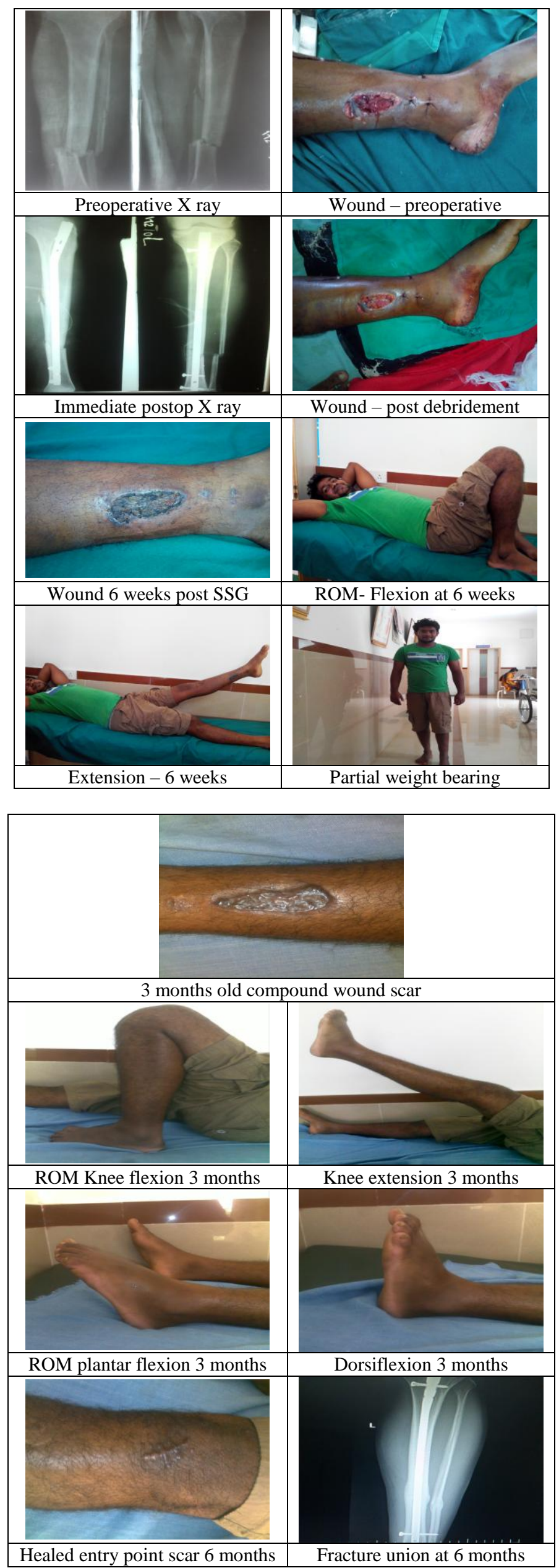

\section{Case Series -02}
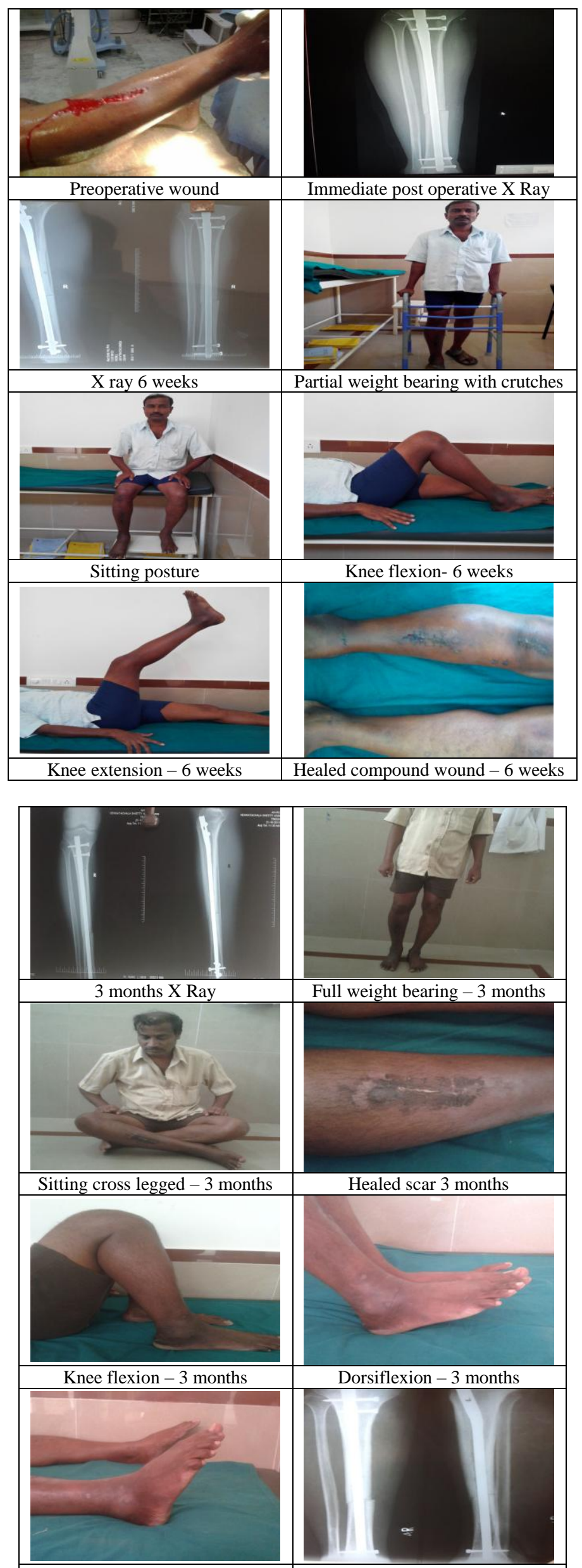

Plantar flexion -3 months 


\section{Discussion}

The optimal management of compound tibial fractures continues to be a problem with several unanswered questions. These fractures, usually caused by high velocity injury, have multiple problems resulting from the poor soft tissue coverage, draining out of the fracture hematoma through the compound wound and limited vascular supply of the tibia, causing mal union, infection and some times resulting in amputation. Recent advances in wound coverage techniques and fixation have decreased the prevalence of these complications, but the optimum management of compound fractures of the tibia is still evolving ${ }^{[16]}$.

There are two major factors related to the lesion that alter the final out come of tibial shaft fractures. The first is the severity of the fracture, characterized according to Nicoll EA ${ }^{[3]}$ by the degree of initial displacement, communition and soft tissue injury. Accordingly, the more severe the fracture, higher the rate of complications and longer the periods of healing will be, whatever the method of fixation used.

The second factor is the damage of the tibial blood supply. In compound fractures, not only is the endosteal circulation disrupted but there is also periosteal circulation disruption after severe soft tissue damage and periosteal stripping from the bone. This emphasizes the necessity to preserve as much as possible the vascularity of the endosteal vessels, using stabilization technique that avoid additional disruption of this blood supply ${ }^{[8]}$.

Johner $\mathrm{R}$ et al $^{[17]}$ reported non-union was twice as common and infection five times more likely when open fractures were treated with plating, so use of a plate is an unattractive treatment option.

External fixation techniques maintain several advantages in the treatment of severely communited open tibial shaft fractures (grade IIIB and C), thus providing early stabilization in patients with polytrauma, improving the survival of injured tissues and permitting turning and mobility to prevent general complications in these patients. Currently, in grade I, II and IIIA open fractures, the use of external fixation has been reduced. Malunion and delayed union are common with this technique ${ }^{[18]}$. To avoid these complications, some authors have recommended the use of secondary intramedullary nailing after external fixation, but this procedure has an increased prevalence of deep infections after delayed conversion or previous pin tract infections.

Of the various intramedullary devices available, the unreamed unlocked nails have produced good results in open tibial fractures but the implant did not adequately stabilize the communited or segmental fractures. In a randomized prospective study comparing external fixation with Ender's nails, Holbrook et al ${ }^{[6]}$ evaluated twenty eight open tibial fractures treated with external fixation and found a 14 percent rate of deep infection, a 21 percent rate of pin tract infection, and a 36 percent rate of malunions. For twenty nine comparable open fractures treated with Ender nails, they reported a 7 percent rate of infection and a 21 percent rate of malunion. The major limitation of ender's nail fixation is lack of axial control.

Interlocking intramedullary nailing with reaming solves the problem of malunions because it provides the ability to control length, angulation and rotation but are associated with high risk of infection in open tibial fractures. However, reaming result in destruction of all vessels in the medullary canal and increases in medullary pressure which leads to infiltration of medullary fat, blood clots and bone debris into the vascular channels. This destruction of endosteal blood vessels along with already compromised vascular supply due to periosteal stripping and soft tissue damage causes considerable bone necrosis and accounted for high rate of infection and non-union in open tibial fractures ${ }^{[19]}$.

Smith $\mathrm{JE}^{20}$ found a rate of infection of 33 percent in a series of 18 open tibial fractures treated with intramedullary nailing with reaming, most of the fractures associated with severe soft tissue injury.

Some truamatologists believe that intramedullary nailing with reaming may be used safely for fractures with less severe wounds. Klemm KW et al (53) reported that six infections (6.5 percent) developed after the use of interlocking intramedullary nailing with reaming in a large series of ninety-three grade - I open tibial fractures ${ }^{[21]}$.

Intramedullary nailing without reaming is less damaging to the endosteal blood supply than is nailing with reaming and historically it has resulted in lower rates of infection. Whittle AP et al ${ }^{[16]}$, evaluated the cortical blood supply of canine tibiae after nailing with and without reaming. They found that reaming disrupts an average of 70 percent of the cortical blood supply, while insertion of a nail without reaming disrupts the blood supply in only the inner third of the cortex. This is especially important in the treatment of open fractures in which the outer cortical blood supply may be damaged by periosteal stripping. Until recently, nails used without reaming could not be locked to the major fracture fragments because small diameter interlocking tibial nails were not available, and stability of communited fractures or more proximal or distal fractures of the tibial shaft could not be achieved.

Lottes JO ${ }^{[22]}$ reported a 7.2 percent rate of infection after treatment of 256 open tibial fractures with the use of his nail without reaming. The 27 percent rate of malunions in the series, Swanson TV et al ${ }^{[23]}$ demonstrates that malunions can be a problem even for fractures that have been judged to be axially stable.

Therefore, unreamed interlocking intramedullary nailing combines the most desirable features of external skeletal fixation and of non-locking nailing without reaming. Length, alignment and rotation are controlled, the soft tissues are easily accessible and some endosteal blood supply is preserved. These factors should lower the rates of infection and malunions and expand the use of intramedullary nails to fractures near the metaphysis and to those with more severe communition and soft tissue injury.

In current series 50 cases of compound fractures of tibia were treated by unreamed interlocking intramedullary nailing over a period of two years. They were followed up for an average 18 months with 4 visits. The purpose of this study was to evaluate the end results of treatment in these patients. These cases were of different age groups, occurred in both sexes and the fracture were of different types and at different levels.

\section{Age Distribution}

The average age of all cases was bimodal in distribution between 20 to 30 yrs and 41 to 50 years with $30 \%$ incidence in both age groups.

The average age in a study of 50 open fractures of tibia conducted by the Whittle AP et al ${ }^{[16]}$ showed that the average age was 34 years. In a study of 43 open fractures of tibia conducted by the Singer RW et al ${ }^{[23]}$ the average age was 36 years. In another study of 72 open fractures of tibia conducted by Bonatus $\mathrm{T}$ et al $^{[24]}$ the average age was 30.3 years. 


\section{Sex Distribution}

There were 33 male and 17 female patients, which shows a preponderance in male population. The sex distribution in a study by Bonatus $\mathrm{T}$ et al $^{[24]}$ showed that there were 52 men and 19 women. In a study by Singer RW et al ${ }^{[23]}$ there were 30 males and 11 females.

\section{Nature of Violence}

Majority of the cases sustained fractures from road traffic accidents. Among R.T.A accidents 52\% of the cases reported as result of motor cycle accidents and $34 \%$ for motor vehicle and $14 \%$ pedestrian accidents.

A series reported by Singer RW et al ${ }^{[23]} 54.16 \%$ fractures were due to motor vehicle accidents. In another series reported by Whittle AP et al ${ }^{[16]}$ most common mode of injury was pedestrian -automobile accident 23 cases (46\%).

\section{Results}

In several reported series as well as in our series, compound fractures of tibia treated with unreamed interlocking intramedullary nailing have given excellent results. In our series 41 fractures $(82 \%)$ united within 6 months of injury, which is comparable with the other series as well.

The delay in union was noticed in 06 patients, three patients with extensive soft tissue injury and delay in performing the surgery due to associated injuries, three patients due to severe fracture communition. The physiological and stable fixation with unreamed interlocking intramedullary nailing showed lower rates of infection and malunions and expanded the use of intramedullary locked nails to the tibial fractures with any degree of communition and soft tissue injury.

In the current series, there was 04 deep infections (08\%) in type III B open fracture and 09 superficial infection (18\%). The incidence of deep infection (8\%) compares favorably with other series reporting rate of $2.4 \%$ to $11.6 \%$ The infection rate using unreamed nails is favorably low compared with external fixation (6-14\%) deep infection rates and other methods.

A malunions was defined as angulation in a coronal plane (varus -valgus) $>5^{0}$, saggital plane (anterior -posterior) angulation of $>10^{\circ}$ or $>10 \mathrm{~mm}$ of shortening. In our series, 05 cases of malunions occurred $(10 \%)$. These results are comparable with the results of unreamed interlocked intramedullary nailing of compound tibial fractures from other center's.

On the basis of this study, we now recommend dynamization of most statically locked nails at 8-12 weeks if callus is not evident to promote fracture union and to avoid fracture of the inter locking screws. Our results were comparable with other series of studies.

In our series, 33 patients had (66\%) full range of knee motion, in 40 patients $(80 \%)$ full range of ankle motion at 14 weeks of injury. These results are comparable with other series of studies.

In our series, no patient developed fat embolism, compartment syndrome, peroneal nerve palsy and reflex sympathetic dystrophy.

At the end of the study each patient was individually asked regarding their opinion about the surgery and their return to premorbid status. 41 patients $(82 \%)$ were pleased, 06 patients (12\%) were satisfied and 03 patients $(6 \%)$ were unhappy.

\section{Conclusion}

1. Unreamed inter locking nailing with the help of an image intensifier seems a good option in compound fractures of tibia.
2. Promotes early fracture union as it does not further compromise vascularity of the fracture site.

3. Early mobilization of the patient helps in reducing fracture disease and reduces sickness absenteeism.

4. Minimal loss of blood during the procedure.

5. Associated with low risk of infection.

6. Early soft tissue coverage, fracture dynamization at 8-10 weeks if union does not progress, to avoid the complications such as non-union or delayed union.

7. Strict adherence to technical principles during nailing might have prevented some of the complications that developed in this series.

8. Minimizes hospital stay and early return to activities.

9. Acceptable complication rates as compared to other modalities of treatment.

10. Unreamed nailing has low incidence of compartment syndrome, peroneal nerve palsy and is acceptable in compound fractures as compared to reamed nailing.

\section{Summary}

Fifty patients with compound fractures of the tibia were treated with wound debridement and unreamed interlocking nail during the period from June 2013 to September 2016, at Adichunchanagiri institute of medical sciences, B G Nagara, Mandya district. All the cases were fresh fractures and traumatic in nature.

Fifty patients with compound fractures of the tibia were available for the study. They were followed for a period of 18 months. Our aim was to treat these fractures by closed reduction internal fixation using an unreamed interlocking nail.

The age distribution of patients with these fractures was bimodal between 20 to 30 and 41 to 50years. Males predominated in our study.

Even though compound fractures of tibia occurs as result of high velocity trauma which is seen most commonly in motor vehicle accidents, our study was conducted in a rural setup where majority of the patients were motor cycle users hence our result which shows $52 \%$ of patients with fractures were motor cycle users followed by motor vehicle accidents.

In our series most of them are Gustilo type II with 31 fractures (62\%) type IIIA 12 fractures (24\%) and type IIIB 07 fractures (14\%), 19 fractures were oblique followed by 13 comminuted, 11 transverse and 7 spiral fractures. Most of the fractures $60 \%$ occurred at the junction of middle -distal third of tibia. All the patients were examined clinically and radio graphically, including detail history of pre-morbid status and occupation at the time of admission. Patients fulfilling the inclusion criteria were only included in the study.

Emergency irrigation and immediate debridement of the compound fracture was done. Patients were operated as early as possible once the general condition of the patients was stable and fit for surgery. In most of the cases, the surgery was performed within $6 \mathrm{hrs}$ of the trauma.

In all of the cases a midline patellar tendon splitting approach was used for nail insertion. Our mean operating time was 75 minutes (range $60 \mathrm{~min}$ to $120 \mathrm{~min}$ ). During the post-operative period all the patients were mobilized as early as possible depending upon the fracture stability, tolerance level of the patients and general condition. 36 fractures united within 6 months of injury and 06 cases of delayed union which united within 36 weeks. 03 patients with Gustillo IIIB with communition had nonunion 10 months after the injury who underwent exchange nailing with bigger size nail and bone grafting. 
In 33 patients (66\%) full range of knee motion started by 12 weeks. More than $80 \%$ of knee motion was seen in 13 cases. In 04 cases less than $75 \%$ of knee motion was achieved $(5 \%)$. In 40 patients $(80 \%)$ full range of ankle motion at 12 weeks.

09 patients developed superficial infection. All were healed with antibiotics. 04 patients developed deep infection in Gustilo type III A \& B open fractures which healed with IV antibiotics, wound debridement and soleal flap.

Results were excellent in $62 \%$ of patients, Good in $20 \%$, fair in $12 \%$ and poor in $6 \%$ of patients.

Intramedullary nailing without reaming is a feasible option in compound fractures of tibia up to Gustilo type IIIB. Image intensifier has revolutionized the treatment of tibial shaft fractures by making the technique more easier.

The present series shows that compound fractures of the tibia, managed well with unreamed intramedullary nailing, involves minimal surgical trauma and minimal blood loss. It provides the advantages of early mobilization, lower rates of infection, delayed union, mal union, and non-union compared to other modalities of treatment. To achieve these goals, we recommend an early and immediate debridement followed by skeletal stabilization with an unreamed interlocking nail and early wound coverage. If union does not progress by 8 to 10 weeks, then we recommend dynamization to prevent the unwanted complications like nonunion or delayed union. Advantage of interlocking nails is early mobilization of the patient which helps in reducing fracture disease and reduces sickness absenteeism.

In our series we found that unreamed interlocking nailing in open fractures of tibial shaft is feasible and showed excellent and good results in $82 \%$ patients with minimal complications.

\section{References}

1. Bucholz and Heckman's Rockwood Greens: Fractures In Adults, Vol 1:7th edition Lippincott Williams and Wilkins Company, USA. 2010, 284-301.

2. Terry Canale's Campbell's Operative Orthopaedics Vol $3,11^{\text {th }}$ edition, Mosby publishers. 2008, 3025-3072.

3. Nicoll EA. fractures of the tibial shaft; A survey of 705 cases. J Bone Joint Surg. 1964; 46B:373-387.

4. Watson Jones: Injuries of the leg Chapter-32in Watson Jones fractures and joint injuries 6th Edn, Wilson JN (Ed), B.I. Churchill Livingstone, New Delhi. 1998, 387.

5. Ruedi T, Webb JK, Allgoer M. experience with the dynamic compression plate (DCP) in 418 recent fractures of tibial shaft Injury. 1976; 7:252-257.

6. Holbrook JL, Swiontiowski MF, Sanders R. treatment of open fractures of the tibial shaft: Ender nailing versus external fixation; a randomised prospective comparison. J Bone Joint Surg. 1989; 71A:1231-1238.

7. Charley J. tractures of the shaft of tibia. The closed treatment of common fractures, Edinburg, Churchill Livingstone. 1961, 209-249.

8. Rhinelander FW. Tibial blood supply in relation to fracture healing. Clin Orthop. 1974; 105:34-81.

9. Ellis $H$. the speed of healing after fracture of th tibial shaft. J Bone Jiont Surg. 1958; 40B:42-46.

10. Gustilo RB, Anderson JT. prevention of infection in the treatment of one thousand and twenty-five open fractures of long bones. Retrospective and proxpective analysis. J Bone Joint Surg. 1976; 58A:453-458.

11. Gustilo RB, Mendoza RM, Williams DN. problems in the management of type III (severe) open fractures: A new classification of type III open fractures. J Trauma $1984 ; 24: 742-746$.
12. Gustilo RB, Merkow RL, Templeman D. current concepts review: the management of open fractures. J Bone Joint Surg. 1990; 72A:299-304.

13. Ruedi TH, Border JR, Algoer M. classification of soft tissue injury. in manual of internal fixation, techniques recommended by the AO/ASIF group, third edition, : edt, Muller ME, Algoer M, Springer Verlig, newyork, 1990: 151.

14. Dehne E, Metzcw, Deffer PA et al. nonoperative treatment of the fractured tibia by immediate weight bearing. J Trauma. 1961; 1:514.

15. Muller CA, Dietrich M, Morakis P, Pfister U. Clinical results of primary intramedullary osteosynthesis with the unreamed AO? ASIF tibial intramedullary nail of open tibial shaft fractures. Unfallchirurg, 1998; 101(11):832837.

16. Whittle AP, Russell TA, Taylor JC, Lavelle DG. Treatmen to open fractures of the tibial shaft with the use of interlocking nailing without reaming. J Bone Joint Surg. 1992; 74A:1162-1171

17. Johner R, Wrohs O. classification of tibial shaft fractures and correlation with results after rigid internal fixation. Clin orthop. 1983; 178:7-25

18. Whittle AP. fracture of lower extremity. chapter -47 in Campbell's operative Orthopaedic, 9th edn,Canale ST(Ed), Mosby, New York. 1998, 2067-2094.

19. Rhinelander FW. effects of medullary nailing of the normal blood supply of diaphyseal cortex. Clin Orthop. 1998; 350:5-17.

20. Smith JE. Results of early and delayed internal fixation for tibial shaft fractures: A review of 470 fractures ".J Bone Joint Surgery (Br). 1974; 56-B:469-477.

21. Klemm KW, Borner, Mortin. Inter locking nailing of complex fractures of the femur and tibia Clin orthop. 1986; 212:89-100.

22. Lottes JO. Medullary nailing of the tibia with the triflange nail. Clin Orthop. 1974; 105:253.

23. Singer RW, Kellam JF. Open tibial diaphyseal fractures: Results of unreamed locked intramedullary nailing". Clin Orthop. 1995; 315:114-118.

24. Bonatus T, Oslan SA, Lees, Chapman MW. Non reamed locking intramedullary nailing for open fractures of the tibia. Clin Orthop. 1997; 339:58-64.

25. Swanson TV, Speigel JD, Sutherland TB, Bray TJ, Chapman MW. A prospective, comparative study of the Lottes nail versus external fixation in 100 open tibial fractures". Orthop Trans. 1990; 14:716-717. 